\title{
Prevalensi Mikropenis pada Murid Taman Kanak - Kanak
}

\author{
Hakimi, Charles Darwin Siregar, Melda Deliana
}

Penis kecil yang sering dikeluhkan orang tua pada umumnya mengenai ukuran panjangnya. Sebenarnya selain dimensi panjang penis, diameter maupun konsistensi penis perlu diperhatikan juga apakah normal atau tidak. Penelitian ini bertujuan untuk mengetahui ukuran penis anak usia 2-6 tahun di Kelompok Bermain dan Taman Kanakkanak. Penelitian ini merupakan studi deskriptif. Data penelitian diperoleh dari kunjungan pada empat Taman Kanak-kanak (TK) di Kota Madya Medan yaitu TK Harapan, TK Al-Azhar, TK Al-Ikhsan, dan TK Yayasan Pendidikan Shafiyyatul Amaliyyah (YPSA) pada tanggal 16-19 Oktober 2004. Responden pada penelitian ini berjumlah 107 anak berusia 2- 6 tahun. Diagnosis mikropenis ditegakkan bila ukuran panjang penis kurang dari -2,5 SD untuk usia tanpa disertai kelainan anatomis penis sedangkan small penis adalah bila ukuran panjang penis berada di antara nilai rerata dan $-2,5$ SD. Dijumpai 9 anak dengan gizi lebih (>NCHS), 2 anak obesitas (IMT>P95) , 7 anak gizi baik (P3- NCHS) dan 91 anak gizi kurang (<NCHS). Pengukuran tinggi badan dijumpai 2 anak perawakan tinggi ( $>\mathrm{NCHS}), 3$ anak perawakan pendek $(<\mathrm{NCHS})$, dan 102 anak perawakan normal (P3- NCHS). Pada penelitian ini ditemui 20 kasus mikropenis (18,7\%), small penis ditemukan 77 kasus (72\%) sedangkan yang memiliki ukuran penis normal 10 orang $(9,4 \%)$.

Kata kunci: mikropenis, hormonal

M ikropenis adalah ukuran panjang penis dalam keadaan diregang yang kurang dari $-2,5$ SD di bawah rerata menurut umur dan status perkembangan pubertas. Pemeriksaan yang akurat penting untuk mengetahui adanya mikropenis. Mikropenis harus dibedakan dengan bidden penis syndrome, yaitu penis tertanam pada lemak suprapubik. ${ }^{1}$ Pengalaman klinis menunjukkan bahwa kunjungan untuk konsultasi mikropenis meningkat dari tahun ke tahun di Poliklinik Endokrinologi Anak RSCM. Tridjaya B, dkk menemukan 23 kasus mikropenis di Poliklinik Endokrinologi Anak RSCM

\footnotetext{
Alamat korespondensi :

Dr. Hakimi, Sp.A, Dr. Charles Darwin Siregar, Sp.A,

Dr. Melda Deliana, Sp.A.

Bagian Ilmu Kesehatan Anak FK USU/RS HAM Jalan Bunga Lau No. 17

Telepon : (061) 8361721, Fax : (061) 8361721 Medan
}

tahun 1998-1999. Rerata usia penderita ketika datang pertama kali berobat adalah 9,6 tahun dan keluhan mikropenis terutama terjadi pada usia peripubertas pada saat terjadi disosiasi pertumbuhan fisik dan penis. ${ }^{2}$

Penis kecil yang sering dikeluhkan orang tua biasanya mengenai ukuran panjangnya saja. Sebenarnya selain dimensi panjang penis, diameter maupun konsistensi penis perlu diperhatikan juga apakah normal atau tidak, karena lebih berhubungan dengan normal tidaknya jaringan penis. Pengobatan mikropenis tanpa adanya pengertian mengenai definisi dan kelainan hormonal yang mendasarinya, dapat menyebabkan gangguan pertumbuhan linier dan gangguan perkembangan pubertas. ${ }^{3}$ Mikropenis dapat disebabkan oleh hipogonadotropik hipogonadisme dapat juga merupakan kombinasi dengan defisiensi hipofisis yang lain khususnya defisiensi growth hormon. Selain itu juga dapat ditemukan pada kasus dengan hipogonadisme primer dan dalam bentuk yang tidak sempurna dari sindrom insensitivitas androgen. ${ }^{4}$ 
Terapi yang dilakukan adalah pemberian testosteron ester $25 \mathrm{mg}$ intramuskular, sebanyak 4 dosis dengan interval 3 minggu. Biasanya akan terjadi pertambahan panjang penis yang bermakna. ${ }^{2}$

Penelitian ini bertujuan untuk mengetahui ukuran penis anak usia 2-6 tahun di Kelompok Bermain dan Taman Kanak-kanak.

\section{Bahan dan cara}

Penelitian ini merupakan studi deskriptif. Data penelitian diperoleh dari kunjungan pada empat Taman Kanak-kanak (TK) di Kota Madya Medan yaitu TK Harapan, TK Al-Azhar, TK Al-Ikhsan, dan TK Yayasan Pendidikan Shafiyyatul Amaliyyah (YPSA) pada tanggal 16-19 Oktober 2004. Responden pada penelitian ini adalah anak usia 2- 6 tahun pada kelompok bermain dan taman kanak-kanak. Setelah memberikan inform concent dan tidak ada kelainan morfologis penis maka responden diikutsertakan dalam penelitian.

Penis diukur pada anak dalam keadaan supinasi. Panjang penis diukur dari basis penis sampai glans, bukan preputium. Glans penis kemudian dipegang dengan ibu jari dan telunjuk dan ditarik sejauh mungkin (stretched) secara vertikal. Penis yang ditarik dalam keadaan tegak tersebut kemudian disandarkan pada spatula kayu dan diukur. Spatula kayu sendiri ditekan sampai mencapai tulang pubis (spatula terasa terhambat ketika mencapai tulang pubis). Pengukuran dilakukan sebanyak tiga kali dan nilai reratanya digunakan sebagai data panjang penis. Ukuran penis yang diperoleh kemudian dikonfirmasikan pada tabel rerata ukuran panjang penis sebagai berikut: ${ }^{5}$

Diagnosis mikropenis ditegakkan bila ukuran panjang penis kurang dari $-2,5$ SD untuk usia tanpa disertai kelainan anatomis penis sedangkan small penis adalah bila ukuran panjang penis berada di antara nilai rerata dan $-2,5$ SD. Pengukuran dilakukan oleh satu orang peneliti dengan variabilitas pengukuran $0,1 \mathrm{~cm}$.

Pengukuran status antropometri yaitu berat badan terhadap umur, tinggi badan terhadap umur dan lingkar kepala. Tinggi badan tanpa alas kaki diukur menggunakan Staturemeter dengan sensitivitas $0,1 \mathrm{~cm}$. Anak berdiri dengan posisi tegak lurus ke depan. Berat badan diukur dengan timbangan merek Mic dengan sensitivitas $0,1 \mathrm{~kg}$. Anak berdiri tanpa alas kaki, posisi tegak pada tengah plat. Kriteria penilaian berat berat badan dan tinggi badan adalah menurut 2000 Centers for Disease Control (CDC) Growth Charts. Jika tinggi badan $<\mathrm{P} 3$ disebut perawakan pendek, di antara P3-P97 normal, dan $>$ P97 perawakan tinggi. Sedangkan berat badan $<$ P3 disebut gizi kurang, antara P3-P97 gizi baik, dan $>$ P97 gizi lebih. ${ }^{6}$ Untuk mengetahui obesitas diukur index massa tubuh yaitu dengan menghitung berat badan (kilogram) dibagi dengan tinggi badan (meter) pangkat dua. Obesitas jika IMT $>$ P95 dan berat badan lebih IMT>P85. ${ }^{7}$ Lingkar kepala diukur dengan pita pengukur yang ditempatkan melingkar di kepala pasien melalui bagian yang paling menonjol (protuberantia occipitalis) dan dahi (glabella) dengan sensitivitas $0,1 \mathrm{~cm}$. Penilaian dilakukan berdasarkan kurva lingkar kepala yang dikutip dengan modifikasi dari Nellhaus G, jika <-2SD disebut mikrosefali, antara $-2 \mathrm{SD}$ sampai $+2 \mathrm{SD}$ normal, dan $>+2 \mathrm{SD}$ makrosefali. ${ }^{8}$

\section{Hasil}

Penelitian dilakukan terhadap 135 orang anak lakilaki dari empat TK di Kota Medan. Dua puluh delapan orang dikeluarkan dari penelitian, 26 orang tidak dilakukan pengukuran penis karena anak tidak koperatif, 1 orang menderita fimosis, dan 1 orang tidak dapat dilakukan pengukuran karena penis dalam keadaan ereksi.

Tabel 1. Rerata ukuran panjang penis berdasarkan umur

\begin{tabular}{lcc}
\hline Usia & $\begin{array}{c}\text { Rerata } \pm \text { SD } \\
(\mathrm{cm})\end{array}$ & $\begin{array}{c}+2,5 \text { SD } \\
(\mathrm{cm})\end{array}$ \\
\hline Lahir & & \\
Usia gestasi 30 minggu & $2,7 \pm 0,5$ & 1,5 \\
Usia gestasi 34 minggu & $3,0 \pm 0,4$ & 2,0 \\
Cukup bulan & $3,5 \pm 0,4$ & 2,5 \\
0-5 bulan & $3,8 \pm 0,8$ & 1,8 \\
6-12 bulan & $4,1 \pm 0,8$ & 2,1 \\
1-2 tahun & $5,0 \pm 0,8$ & 2,6 \\
2-3 tahun & $5,4 \pm 1,0$ & 3,0 \\
3-4 tahun & $5,6 \pm 0,7$ & 2,9 \\
4-5 tahun & $6,0 \pm 0,9$ & 3,4 \\
5-7 tahun & $6,3 \pm 1,0$ & 3,8 \\
7-9 tahun & $6,3 \pm 1,0$ & 3,8 \\
9-11 tahun & $6,3 \pm 1,0$ & 3,8 \\
\hline
\end{tabular}


Subjek penelitian dari kelompok bermain 17 orang, TK A 44 orang, dan TK B 74 orang. Hasil pengukuran berat badan menunjukkan 91 orang dengan berat badan berada antara persentil 3-97 NHCS, 7 orang berada pada persentil $<3$ NCHS, dan 9 orang pada persentil $>97$ NCHS 2 orang di antaranya dengan IMT>P95 dan 7 orang lainnya normal. Tinggi badan subjek ditemukan bahwa 102 orang berada antara NCHS persentil 3-97, 3 orang pada persentil $<3$ NCHS, dan 2 orang pada persentil >97 NCHS. Sedangkan hasil pengukuran lingkar kepala menunjukkan 100 orang berada di antara -2SD sampai $+2 \mathrm{SD}, 5$ orang pada $<-2 \mathrm{SD}$, dan 2 orang pada $>+2 \mathrm{SD}$ Kurva Nellhause G. (Tabel 2)

Tabel 2. Karakteristik subyek penelitian

\begin{tabular}{lc}
\hline Krakteristik sampel & Total (orang) \\
\hline Kelompok Bermain (1-3 tahun) & 17 \\
TK A (4-5 tahun) & 44 \\
TK B (5-6 tahun) & 74 \\
Berat Badan & \\
$\quad$ <3 NCHS & 7 \\
p3-97 NCHS & 91 \\
>p97: normal & 7 \\
$\quad$ obesitas & 2 \\
Tinggi Badan (NCHS) & \\
$\quad$ <p3 & 3 \\
p3 - 97 & 102 \\
$\quad>$ p97 & 2 \\
Lingkar kepala & \\
-2SD sampai +2SD & 100 \\
<-2SD & 5 \\
> +2SD & 2 \\
\hline
\end{tabular}

Hasil pengukuran panjang penis menunjukkan 20 kasus dengan mikropenis (18,7\%), 77 anak dengan small penis $(72 \%)$, dan ukuran panjang penis yang normal dengan 10 orang $(9,4 \%)$ (Tabel 3)

Tabel 3. Ukuran penis

\begin{tabular}{lcc}
\hline Ukuran penis & Jumlah (orang) & Persentase (\%) \\
\hline Normal & 10 & 9,4 \\
Small penis & 77 & 72,0 \\
Mikropenis & 20 & 18,7 \\
\hline Jumlah & 107 & 100 \\
\hline
\end{tabular}

\section{Diskusi}

Sebagaimana telah diuraikan, definisi mikropenis yaitu organ penis yang ukuran panjangnya kurang dari -2,5 SD untuk usia dan status perkembangan pubertasnya tanpa disertai kelainan struktur penis. ${ }^{3}$ Pada penelitian ini ada satu orang anak yang menderita fimosis sehingga dikeluarkan dari penelitian serta satu orang anak dengan penis dalam keadaan ereksi sehingga tidak dapat dilakukan pengukuran terhadap panjang penisnya.

Pada anak gemuk, penis yang normal akan tampak kecil karena penis tertanam dalam-dalam pada lipatan lemak supra pubik. Semakin gemuk anak akan semakin tebal lipatan lemak tersebut sehingga penis akan semakin terbenam di dalam lipatan lemak tersebut, sehingga penis akan tampak semakin kecil. ${ }^{3}$ Selain panjang penis diukur juga status antropometri pada anak-anak tersebut yaitu tinggi badan, berat badan, dan lingkar kepala. Dijumpai 9 orang anak gizi lebih (>P97 NCHS), 2 orang anak obesitas (IMT >P95 NCHS), 7 anak gizi baik (P3-P97 NCHS) dan 91 anak gizi kurang $(<\mathrm{P} 3$ NCHS). Sedangkan untuk tinggi badan dijumpai 2 orang anak perawakan tinggi ( $>$ P97 NCHS), 3 orang anak perawakan pendek (<P3 NCHS), dan 102 anak perawakan normal (P3-P97 NCHS).

Mikropenis dapat menimbulkan masalah psikososial karena penis merupakan identitas jenis kelamin, posisi berkemih yang normal, serta untuk fungsi seksual. Masalah ini dapat diatasi dengan evaluasi dan pengobatan yang dilakukan secara dini. ${ }^{9}$ Hal yang paling penting adalah agar anak tersebut dapat mencapai perkembangan penis yang sesuai untuk fungsi seksual sebagai seorang dewasa. ${ }^{10,11}$

Penelitian ini dilakukan di taman kanak-kanak untuk mengukur penis setiap murid laki-laki pada kelompok bermain, TK A dan TK B untuk mendeteksi mikropenis sedini mungkin. Dari 107 anak yang dimasukkan ke dalam penelitian, dijumpai 20 kasus mikropenis $(18,7 \%)$ dan ternyata banyak yang menderita small penis yaitu 77 kasus $(72 \%)$ sedangkan yang memiliki ukuran penis normal hanya 10 orang $(9,4 \%)$.

Pengobatan testosteron sangat bermanfaat pada mikropenis dengan respon terapi rerata dari panjang awal -3SD menjadi -6SD atau terjadi penambahan panjang penis sebesar $78 \%{ }^{3}$ Batubara, mendapatkan bahwa pemberian testosterone $25 \mathrm{mg}$ setiap 3 minggu 
sebanyak empat kali tidak mempercepat usia tulang anak yang datang dengan keluhan mikropenis. ${ }^{11}$ Pada penelitian ini, anak-anak yang menderita mikropenis dianjurkan untuk kontrol ulang dan mendapatkan terapi testosteron.

\section{Kesimpulan}

Penelitian ini dilakukan terhadap 135 orang anak lakilaki dari empat TK di Kota Medan sebanyak 107 orang anak. Pada pengukuran panjang penis dijumpai 20 kasus mikropenis $(18,7 \%), 77$ orang dengan small penis $(72,0 \%)$, dan ukuran panjang penis yang normal dijumpai pada 10 orang $(9,4 \%)$.

Ucapan terima kasih kepada dr Bugis Mardina Lubis dan dr Febrina Zulhidayati Siregar yang telah membantu mengumpulkan data-data penelitian.

\section{Daftar Pustaka}

1. Lifshitz F. Micropenis. Dalam: Lifshitz F, penyunting. Pediatric endocrinology. Edisi ke-3. New York: Marcel Dekker Inc, 1996. h. 297-8.

2. Tridjaja B, Batubara JRL, Pulungan A. Pengobatan testosteron pada mikropenis. Sari Pediatri 2002; 4: 63-6.

3. Batubara JRL. Mikropenis. Dibacakan di Symposium Ambiguus genitalia KONIKA IX Semarang 1993.

4. Wales JKH, Rogol AD, Wit JM. Micropenis. Dalam: Wales JKH, Rogol AD, Wit JM, penyunting. Color atlas of pediatric endocrinology and growth. Spain: Times Mirror International Publisher Limited, 1996. h. 112-3.

5. Moore WT, Eastman RC. Micropenis. Dalam: Moore WT, Eastman RC, penyunting. Diagnostic endocrinology. Edisi ke-2. Missouri: Mosby-Year Book, 1990. h. 61-3.

6. CDC Growth Charts for the United States 2000: Methods and Development. Department of Health and Human Services. Centers for Disease Control and Prevention, No 246, 2000.

7. Barness LA, Curran JS. Nutrition. Dalam: Behrman RE, Kliegman RM, Arvin AM, penyunting. Nelson text book of pediatrics. Edisi ke-15. Philadelphia: Saunders, 1996. h. 141-84.

8. Soetomenggolo TS. Prosedur diagnostik. Dalam: Soetomenggolo TS, Ismael S, penyunting. Buku ajar neurologi anak. Jakarta: Ikatan Dokter Anak Indonesia, 2000. h. 36-59.

9. Bourgeois MJ. Microphallus. URL: http://www. emedicine.com/emerg/topic 404.htm

10. Greenspan FS, Gardner DG. Unclasified forms of abnormal sexual development in males. Dalam: Greenspan FS, Gardner DG, penyunting. Basic \& clinical endocrinology. Edisi ke-2. United States of America: McGrawHill Companies, 2004. h. 599-600.

11. Batubara JRL. Pengobatan testosteron pada mikropenis. Dibacakan di Symposium Ambiguus genitalia KONIKA IX Semarang 1993.

12. Hung W. Growth and development: normal and variants. Dalam: Moore WT, Eastman RC, penyunting. Diagnostic endocrinology. Edisi ke-2. Missouri: MosbyYear Book, 1996. h. 61-3. 